\title{
Pengaruh Pendelegasian Wewenang Dan Komitmen Organisasi Terhadap Kinerja Manajerial Pada Organisasi Perangkat Daerah Pemerintah Kota Tangerang
}

\author{
Rabitha Fazira1) \\ Lena Erdawati2) \\ Universitas Muhammadiyah Tangerang, Banten, Indonesia
}

\begin{abstract}
Abstrak
Penelitian ini bertujuan untuk mengetahui besarnya pengaruh pendelegasian wewenang Dan komitmen organisasi terhadap kinerja manajerial pada organisasi perangkat daerah Pemerintahan Kota Tangerang. Dalam hal ini peneliti mendistribusikan Kuisioner kepada 61 orang pegawai Pemkot Kota Tangerang, dimana teknik Analisis data Yang digunakan Dalam penelitian ini yaitu SMART PLS (Partial Least Square). Tahapan analisis dengan metode perancangan model pengukuran, uji model luar (validitas dan reliabilitas), uji model dalam (koefisien jalur), uji model fit (goodness of fit), pengujian hipotesis (resampling bootstrap) dan kesimpulan. Hasil penelitian menemukan bahwa pendelegasian wewenang berpengaruh positif signifikan terhadap kinerja manajerial dan komitmen organisasi berpengaruh positif signifikan terhadap kinerja manajerial.
\end{abstract}

\section{Kata kunci : Pendelegasian Wewenang, Komitmen Organisasi dan Kinerja} Manajerial 


\begin{abstract}
The purpose of this research was to examine the influence of delegation of authority and organizational commitment to managerial performance in the regional government organizations in Tangerang City. This study distributed 61 questionnaires. Data analysis methods used by this research Partial Least Square (PLS). Stages of analysis with the method of designing a measurement model, test the outer model (validity and reliability), test the inner model (path coefficients), test the fit model (goodness of fit), hypothesis testing (resampling bootstraping) and conclusions.The results of the study found that delegation of authority had a significant positive effect on managerial performance and organizational commitment had a significant positive effect on managerialPerformance.
\end{abstract}

Keywords: delegation of authority,organizational commitment, managerial performance 
PRIMANOMICS : JURNAL EKONOMI DAN BISNIS - VOL. 17. NO. 3 (2019)

Versi Online Tersedia di : https://jurnal.ubd.ac.id/index.php/ds

| 1412-632X (Cetak) | 2614-6789 (Online) |

\section{PENDAHULUAN}

Organisasi sektor publik seperti pemerintah daerah dituntut bekerja demi kepentingan masyarakat dan mendorong pemerintah untuk senantiasa tanggap dengan lingkungannya dengan cara memberikan pelayanan terbaik secara transparan dan berkualitas serta adanya pembagian tugas yang baik pada pemerintah tersebut. Tuntutan yang semakin tinggi diajukan terhadap pertanggungjawaban yang diberikan oleh penyelenggara negara atas kepercayaan yang diamanatkan kepada mereka. Kinerja sektor publik sebagian besar dipengaruhi oleh kinerja aparat atau manajerial. Unit-unit kerja organisasi publik diharapkan dapat menciptakan lingkungan kerja yang kondusif dengan menginteraksikan kemampuan pimpinan dan kemampuan bawahan (Putri, 2013).

Kinerja sektor publik didasarkan pada kinerja manajer dan para aparatur pemerintah. Manajer dan para aparatur pemerintah sebagai pelaksana dari kegiatan pemerintahan bertanggung jawab untuk mewujudkan lingkungan kerja yang kondusif dengan menginteraksikan kemampuan pimpinan dan kemampuan bawahan. Faktor yang diduga mempengaruhi kinerja manajerial pada sektor publik adalah pendelegasian wewenang dan komitmen organisasi. Pendelegasian wewenang adalah pemberian wewenang dan tanggung jawab kepada orang yang ditunjuk oleh pemilik otoritas. Atasan memberi kekuasaan kepada staff atau bawahan sehingga dapat melakukan tugas-tugas itu dengan baik dan dapat mempertanggungjawabkan hal-hal yang didelegasikan kepadanya. Pendelegasian wewenang oleh atasan kepada bawahan diperlukan untuk pencapaian efisiensi fungsi dalam organisasi, karena tidak ada satu orang pun yang dapat secara pribadi merampungkan atau secara penuh melaksanakan dan mengawasi semua tugas organisasi.

Komitmen organisasi merupakan dorongan dari dalam individu untuk berbuat sesuatu agar dapat menunjang keberhasilan organisasi sesuai dengan tujuan dan lebih mengutamakan kepentingan organisasi dibandingkan kepentingan sendiri. Manajer akan mengesampingkan kepentingan pribadinya, agar dapat memenuhi kepentingan organisasinya terlebih dahulu. Hal ini tentu akan meningkatkan kinerja manajerial tersebut.

Beberapa penelitian telah dilakukan untuk mengetahui faktor-faktor yang mempengaruhi kinerja manajerial pada organisasi pemerintah. Penelitian ini bermaksud menguji kembali faktor pendelegasian wewenang dan komitmen organisasi yang diduga berpengaruh terhadap kinerja manajerial dan memilih Organisasi Pemerintah Daerah (OPD) Kota Tangerang sebagai objek penelitian.

\section{Tujuan Penelitian}

Tujuan penelitian ini adalah untuk memperoleh bukti secara empiris mengenai:

1. Pendelegasian wewenang berpengaruh terhadap kinerja manajerial OPD.

2. Komitmen organiasi berpengaruh terhadap kinerja manajerial OPD. 


\section{KAJIAN LITERATUR}

\section{Teori Penetapan Tujuan (Goal-Setting Theory)}

Teori penetapan tujuan (Goal-Setting Theory) adalah salah satu bagian dari teori motivasi yang dikemukakan oleh Edwin Locke pada tahun 1978. Teori penetapan tujuan didasarkan pada bukti bahwa tujuan (gagasan untuk masa depan; kondisi yang diinginkan) memainkan peran penting dalam bertindak. Teori penetapan tujuan adalah model pribadi yang ingin memiliki tujuan, memilih tujuan dan sasaran yang dimaksudkan untuk tujuan tertenru (Birnberg et al., 1990).

Menurut teori ini, salah satu karakteristik perilaku yang memiliki tujuan yang sering diamati adalah bahwa perilaku tersebut terus berlanjut sampai perilaku mencapai penyelesaiannya, setelah seseorang memulai sesuatu (seperti pekerjaan, proyek baru), dia terus menekan sampai tujuan tercapai. Proses penetapan tujuan dapat dilakukan atas prakarsanya sendiri atau dibutuhkan oleh organisasi sebagai suatu kebijakan (Wangmuba dalam Ramandei, 2009). Teori penetapan tujuan menjelaskan hubungan antara tujuan yang ditetapkan dengan kinerja. Konsep dasar dari teori ini adalah bahwa seseorang yang memahami tujuan (apa yang diharapkan organisasi untuk itu) akan mempengaruhi perilaku kerjanya.

\section{Kinerja Manajerial}

Kinerja adalah gambaran pencapaian implementasi suatu kegiatan atau program dalam mewujudkan tujuan, sasaran, misi dan visi organisasi. Secara umum, kinerja merupakan pencapaian yang dapat dicapai oleh organisasi dalam periode tertentu (Bastian, 2006). Pada Permendagri 13 tahun 2006, definisi kinerja adalah keluaran atau hasil dari kegiatan atau program yang akan atau telah dicapai dalam kaitannya dengan penggunaan anggaran dengan kuantitas dan kualitas yang dapat diukur. Menurut pendekatan perilaku dalam manajemen, kinerja adalah kuantitas atau kualitas sesuatu yang dihasilkan atau layanan yang diberikan oleh seseorang yang melakukan pekerjaan (Luthans dalam Febrianti, 2013).

Kinerja manajerial adalah tingkat kemampuan untuk mengelola kegiatan yang mencakup perencanaan, koordinasi, investigasi, negosiasi, negosiasi, mewakili, mengawasi dan mengevaluasi. Definisi kinerja manajerial menurut Mahoney et.al, (1993) adalah kinerja individu anggota organisasi dalam kegiatan manajerial seperti; perencanaan, investigasi, koordinasi, kepegawaian, negosiasi dan perwakilan.

Kinerja manajerial organisasi perangkat daerah (OPD) adalah gambaran mengenai tingkat pencapaiaan sasaran atau tujuan sebagai penjabaran dari visi, misi, dan strategi instansi pemerintah daerah yang mengidentifikasi tingkat keberhasilan atau kegagalan pelaksanaan kegiatan-kegiatan sesuai dengan tugas pokok dan fungsi aparat instansi tersebut (Sedarmayanti, 2004).

\section{Pendelegasian Wewenang}

Menurut Sutarto (2001) dalam Irwan (2013), wewenang adalah hak seseorang untuk mengambil tindakan yang diperlukan agar tugas serta tanggung jawabnya dapat dilaksanakan dengan baik. Pendelegasian wewenang adalah memberikan sebagian pekerjaan atau wewenang oleh delegator (pemberi wewenang) kepada delegate (penerima wewenang) untuk dikerjakannya atas nama delegator (Hasibuan, 2007). 
PRIMANOMICS : JURNAL EKONOMI DAN BISNIS - VOL. 17. NO. 3 (2019)

Versi Online Tersedia di : https://jurnal.ubd.ac.id/index.php/ds

| 1412-632X (Cetak) | 2614-6789 (Online) |

Pendelegasian wewenang adalah pemberian wewenang dan tanggung jawab kepada orang yang ditunjuk oleh pemilik otoritas. Atasan memberi kekuasaan kepada staf atau bawahan sehingga dapat melakukan tugas-tugas itu dengan baik dan dapat mempertanggungjawabkan hal-hal yang didelegasikan kepadanya. Pendelegasian wewenang oleh atasan kepada bawahan diperlukan untuk pencapaian efisiensi fungsi dalam organisasi, karena tidak ada satu orang pun yang dapat secara pribadi merampungkan atau secara penuh melaksanakan dan mengawasi semua tugas organisasi.

\section{Komitmen Organisasi}

Menurut Alwi (2001) dalam Nanda dkk (2013), komitmen organisasi adalah sikap karyawan untuk tetap berada dalam organisasi dan terlibat dalam upaya-upaya mencapai misi, nilai-nilai dan tujuan organisasi. Komitmen organisasi adalah situasi di mana karyawan memihak dan peduli kepada organisasi tertentu dan tujuan mereka, dan berniat untuk mempertahankan keanggotaan mereka dalam organisasi. Komitmen organisasi yang tinggi diperlukan dalam suatu organisasi, karena terciptanya komitmen yang tinggi akan mempengaruhi situasi kerja profesional.

Komitmen organisasi didefinisikan sebagai tingkat kepercayaan dan penerimaan tentang kerja terhadap tujuan organisasi dan mempunyai keinginan untuk tetap dalam organisasi tersebut (Mathis, 2001 dalam Putri, 2013). Komitmen organisasi menunjukan keyakinan dan dukungan yang kuat terhadap nilai dan sasaran (goal) yang ingin dicapai oleh organisasi (Mowday et. al. 1979 dalam Putri, 2013). Komitmen organisasi yang kuat akan mendorong para manajer bawahan berusaha keras mencapai tujuan oraganisasi dan meningkatkan kinerja organisasi.

\section{HIPOTESIS PENELITIAN}

H1: Pendelegasian wewenang berpengaruh positif terhadap kinerja manajerial OPD.

H2: Komitmen Organisasi berpengaruh positif terhadap kinerja manajerial OPD

\section{METODE PENELITIAN}

\section{Jenis Penelitian}

Penelitian ini menggunakan data kuantitatif yaitu data yang diperoleh dari jawaban responden terhadap pertanyaan yang ada dalam kuesioner berupa nilai atau skor. Jenis data yang digunakan adalah data primer, yaitu data yang diperoleh langsungdari responden berupa jawaban terhadap kuesioner dengan mengambil sumber dataPegawai Pemerintah Kota Tangerang.

\section{Populasi dan Sampel}

Populasi dalam penelitian ini adalah seluruh pegawai Pemerintah Kota Tangerang. Sampel penelitian ini didapat dengan kriteria yaitu pegawai eselon II, III dan IV yang terdiri dari Kepala OPD, Sekretaris, Kepala Bidang dan Kepala Bagian yang ada di Dinas Pendapatan, Dinas Pasar dan Dinas Perhubungan 61 orang. 


\section{Definisi dan Operasional Variabel}

Definisi dan operasional variabel yang digunakan dalam penelitian dirangkum dalam tabel berikut ini :

\section{Tabel 1. Definisi Operasional Variabel}

\begin{tabular}{|c|c|c|}
\hline Variabel & Dimensi & Indikator \\
\hline $\begin{array}{l}\text { Pendelegasian } \\
\text { wewenang } \\
\left(X_{3}\right) \\
\text { (Fernando, } \\
2013 \text { ) }\end{array}$ & $\begin{array}{l}\text { 1. Mutasi pegawai } \\
\text { 2. Pengalokasian } \\
\text { anggaran, } \\
\text { 3. Spesifikasi pelaksanaan } \\
\text { tugas, } \\
\text { 4. Keputusan operasional, } \\
\text { Pembuatan keputusan } \\
\text { para pimpinan. }\end{array}$ & $\begin{array}{l}\text { 1. Pengangkatan dan pemindahan } \\
\text { hubungan kerja pegawai dari } \\
\text { pimpinan/kepala dinas atau } \\
\text { instansi, } \\
\text { 2. Berperan dalam alokasi anggaran, } \\
\text { 3. Kesesuaian tugas yang diamanatkan } \\
\text { 3. Pelaksanaan tugas yang sesuai } \\
\text { dengan pedoman yang ditetapkan } \\
\text { 4. Kewenangan membuat keputusan } \\
\text { operasional }\end{array}$ \\
\hline $\begin{array}{l}\text { Komitmen } \\
\text { Organisasi } \\
\left(\mathrm{X}_{4}\right) \\
\text { (Fernando, } \\
2013)\end{array}$ & $\begin{array}{l}\text { 1. Belief yang kuat serta } \\
\text { penerimaan terhadap } \\
\text { tujuan dan nilai } \\
\text { organisasi } \\
\text { 2. Kesiapan untuk bekerja } \\
\text { keras } \\
\text { 3. Keinginan yang kuat } \\
\text { untuk bertahan di } \\
\text { organisasi }\end{array}$ & $\begin{array}{l}\text { 1. Sistem nilai kerja yang sama dengan } \\
\text { organisasi } \\
\text { 2. Kesiapan bekerja sama untuk } \\
\text { pencapaian tujuan organisasi } \\
\text { 3. Peluang organisasi untuk } \\
\text { peningkatan kinerja }\end{array}$ \\
\hline $\begin{array}{l}\text { Kinerja } \\
\text { Manajerial (Y) } \\
\text { (Fernando, } \\
2013 \text { ) }\end{array}$ & $\begin{array}{l}\text { 1. Perencanaan } \\
\text { 2. Investigasi } \\
\text { 3. Koordinasi } \\
\text { 4. Evaluasi } \\
\text { 5. Supervisi } \\
\text { 6. Staffing } \\
\text { 7. Negosiasi } \\
\text { 8. Representasi }\end{array}$ & $\begin{array}{l}\text { 1. Peran penentuan tujuan dan } \\
\text { kebijakan rencana kegiatan } \\
\text { 2. Mengumpulkan informasi berupa } \\
\text { catatan dan laporan } \\
\text { 3. Penyesuaian laporan } \\
\text { 4. Penilaian rencana kerja } \\
\text { 5. Memberi arahan } \\
\text { pengembangan bawahan } \\
\text { 6. Penempatan pegawai } \\
\text { 7. Berperan dalam penentuan kontrak } \\
\text { kerjasama peranan berhubungan } \\
\text { 8. Memiliki peranan } \\
\text { dengan pihak luar } \\
\text { 9. Evaluasi kinerja dan sasaran } \\
\text { keseluruhan kinerja }\end{array}$ \\
\hline
\end{tabular}

Sumber data : data diolah, 2019 
PRIMANOMICS : JURNAL EKONOMI DAN BISNIS - VOL. 17. NO. 3 (2019)

Versi Online Tersedia di : https://jurnal.ubd.ac.id/index.php/ds

| 1412-632X (Cetak) | 2614-6789 (Online) |

\section{Tehnik Analisis Data}

Tehnik analisis data yang dipilih adalah Partial Least Square (PLS) menggunakan perangkat lunak SmartPLS. Langkah-langkah analisis dengan metode sebagai berikut:

a. Merancang Model Pengukuran

b. Uji Outer Model (Validity dan reliability)

c. Uji Inner Model(Path Coeffiecient)

d. Uji Model fit (Goodness of Fit)

e. Uji Hipotesis (Resampling Bootstraping)

\section{HASIL PENELITIAN DAN PEMBAHASAN HASIL PENELITIAN}

Penelitian ini bertujuan untuk membuktikan hipotesis yang dirumuskan diterima atau ditolak. Sebelum melakukan pengujian hipotesis, terlebih dahulu dilakukan pengujian terhadap model pengukuran (outer model) dan pengujian terhadap model struktural (inner model). Berikut ini disajikan gambar hasil output SmartPLS hasil pengujian outer dan inner model :

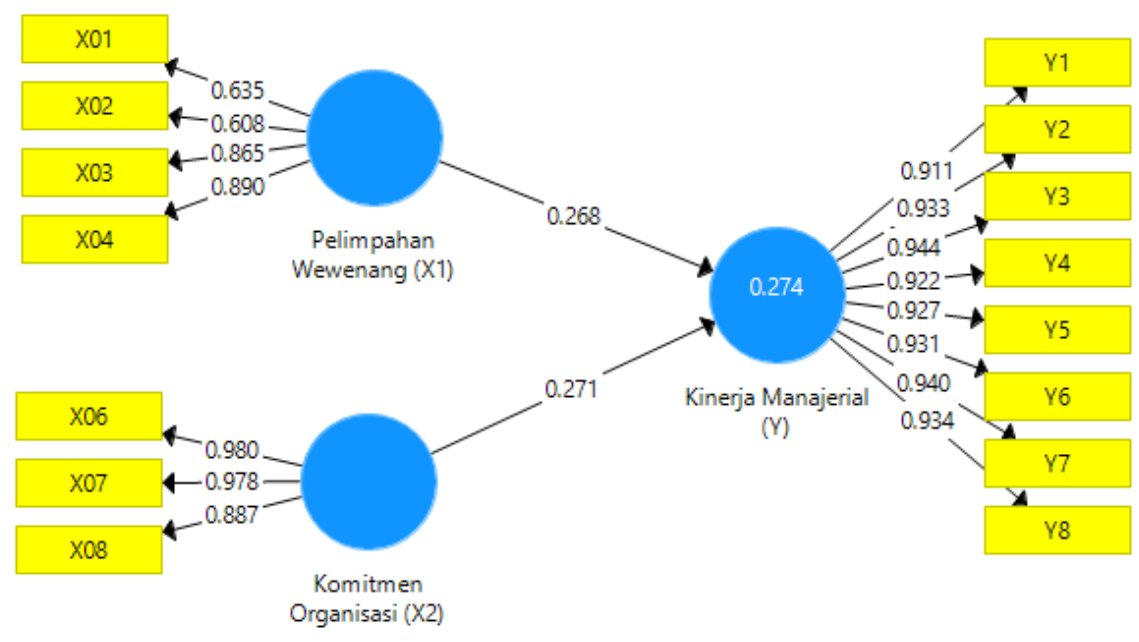

Gambar 1. Model Pengukuran - Outer Model 


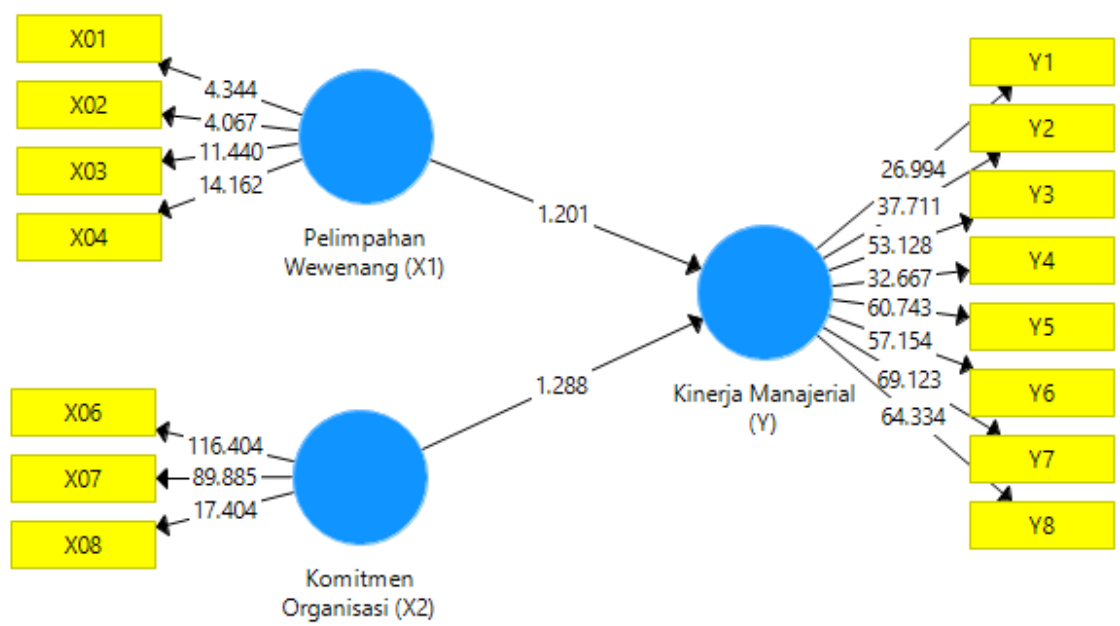

Gambar 2. Model Pengukuran - Inner Model

\section{a. Uji Outer Model}

\section{Uji Validitas - Convergent Validity}

Suatu indikator dinyatakan valid jika nilai loading factor $>0,70$ dan nilai t-hitung $>$ 1,96; sedangkan bila nilai loading factor $\leq$ 0,70 dan nilai t-hitung $\leq 1,96$; maka indikator tersebut dikeluarkan dari model. Berdasarkan Gambar1. seluruh indikator memiliki nilai loading factor $>0,70$; artinya seluruh indikator yang digunakan dalam model dinyatakan valid.

\section{Uji Validitas - Discriminant Validity}

Tabel 2. Nilai Cross Loading

\begin{tabular}{|l|l|l|l|l|}
\multicolumn{1}{c|}{} & \multicolumn{1}{|c|}{ Y } & $\mathbf{X 1}$ & $\mathbf{X 2}$ \\
\hline X01 & 0.319 & 0.635 & 0.239 \\
\hline X02 & 0.214 & 0.608 & 0.196 \\
\hline X03 & 0.400 & 0.958 & 0.865 \\
\hline X04 & 0.523 & 0.974 & 0.890 \\
\hline X06 & 0.551 & 0.875 & 0.980 \\
\hline X07 & 0.510 & 0.889 & 0.978 \\
\hline X08 & 0.349 & 0.732 & 0.887 \\
\hline Y1 & 0.911 & 0.408 & 0.417 \\
\hline Y2 & 0.933 & 0.414 & 0.427 \\
\hline Y3 & 0.944 & 0.458 & 0.484 \\
\hline Y4 & 0.922 & 0.466 & 0.500 \\
\hline Y5 & 0.927 & 0.526 & 0.506 \\
\hline Y6 & 0.931 & 0.487 & 0.455 \\
\hline Y7 & 0.940 & 0.499 & 0.484 \\
\hline Y8 & 0.934 & 0.502 & 0.494 \\
\hline
\end{tabular}

Suatu indikator dapat dinyatakan valid jika nilai cross loading indikator pada variabelnya adalah paling besar dibandingkan dengan indikator pada variabel yang lain. Berdasarkan Tabel 2, nilai cross loadingmasing-masing indikator pada variabel memiliki nilai terbesar dibandingkan nilai cross loading indikator pada variabel lainnya. Sehingga dapat disimpulkan bahwa indikator yang digunakan dalam menyusun variabel memiliki discriminant validity yang baik. 
PRIMANOMICS : JURNAL EKONOMI DAN BISNIS - VOL. 17. No. 3 (2019)

Versi Online Tersedia di : https://jurnal.ubd.ac.id/index.php/ds

$$
\text { | 1412-632X (Cetak) | 2614-6789 (Online) | }
$$

Selain menggunakan nilai cross loading, discriminant validity dapat dilihat melaluinilai average variance extracted (AVE).Suatu indikator (konstruk) dapat dinyatakan memenuhi discriminant validity yang baik jika nilai AVE > 0,50; Berdasarkan Tabel 2, nilai AVEkonstruk lebih besar dari 0,50; maka dapat disimpulkan semua konstruk memiliki convergent validity yang baik.

Tabel 3. NilaiCronbach's Alpha, Composite Reliabilitydan AVE

\begin{tabular}{|l|r|r|r|r|}
\hline & Cronbach's Alpha & \multicolumn{1}{c}{ rho_A } & Composite Reliability & Average Variance Extracted (AVE) \\
\hline Pelimpahan Wewenang $(X 1)$ & 0.767 & 0.835 & 0.842 & 0.578 \\
\hline Komitmen Organisasi $(X 2)$ & 0.946 & 0.992 & 0.965 & 0.901 \\
\hline Kinerja Manajerial $(Y)$ & 0.978 & 0.980 & 0.981 & 0.866 \\
\hline
\end{tabular}

\section{Uji Reliabilitas -Composite Reliabilitydan Cronbach's Alpha}

Suatu variabel dinyatakan reliabel apabila nilaicomposite reliability $>0,70$ dan nilai cronbach's alpha> 0,50;.Berdasarkan Tabel 3, seluruh variabelmemiliki nilai composite reliability $>0,70$ dan memilikinilai cronbach's alpha $>0,50$; sehingga disimpulkan bahwa keseluruhan variabel memiliki tingkat reliabilitas yang tinggi.

\section{b. Uji Inner Model - Path Coefficient}

Uji ini digunakan untuk mengetahui besarnya pengaruh variabel independen terhadap variabel dependen. Berdasarkan Gambar 2, seluruh variabel dalam model ini memiliki nilai path coefficient yang benilai positif. Hal ini menunjukkan bahwa semakin besar nilai path coefficient maka semakin besar pengaruhnya terhadap variabel dependennya. Dan nilai path coefficientterbesar ditunjukkan oleh variabel Komitmen Organisasi (X2) yaitu sebesar 1,288. Sehingga dapat disimpulkan bahwa kinerja manajerial dipengaruhi oleh faktor terbesar yaitu komitmen organisasi $(X 2)$ dibandingkan pendelegasian wewenang $\left(\mathrm{X}_{1}\right)$.

\section{c. Uji Model Fit - Goodness of Fit (GoF)}

Untuk mengevaluasi GoF dalam penelitian ini, maka diperlukan nilai akhir R2 dari tabel $R$ Square. Nilai R2 konstruk $Y$ adalah 0,274; artinya konstruk X1 (Pelimpahan Wewenang), X2 (Komitmen Organisasi), secara simultan mampu menjelaskan variability konstruk Y (Kinerja Manajerial) sebesar 27,4\%.Setelah dilakukan pengolahan data di atas, maka dapat melakukan validasi mode secara keseluruhan, yang dilihat dari Goodness of Fit $(\mathrm{GoF})$ yang formulanya adalah sebagai berikut.

$$
\begin{gathered}
\text { GoF }=\sqrt{\overline{C o m \times R^{2}}} \\
\text { Com }=A V E
\end{gathered}
$$

GoF konstruk Y (Kinerja Manajerial) adalah: $\mathrm{GoF}=\sqrt{ }(0,866 \times 0,279)=0,491$

Nilai GoF terbentang antara 0 sd 1 dengan interpretasi nilai-nilai: 0,1 (GoF kecil), 0,25 (GoF moderat), dan 0,36 (GoF besar). Nilai GoF yang didapat 0,491 dikatakan besar 
karena lebih dari 0,36. Maka dapat disimpulkan, secara keseluruhan model struktur adalah fit. Sehingga pengujian hipotesis dapat dilakukan

\section{d. Uji Hipotesis}

Uji hipotesis pada penelitian ini dilakukan dengan melihat nilai T-Statistics dan nilai $P$-Values. Hipotesis dapat diterima apabila nilai T-Statistics $>$ T-Hitung dan nilai $P$-Values $<$ dari 0,05. Berikut ini hasil pengujian hipotesis yang diperoleh :

\begin{tabular}{|l|c|c|}
\hline \multicolumn{4}{|c|}{ Tabel 4. Nilai T-Statistics dan nilai P-Values } \\
\hline & T Statistics ... & P Values \\
\hline Pelimpahan Wewenang (X1) & 10.154 & 0.000 \\
\hline Komitmen Organisasi $(\mathrm{X} 2)$ & 30.872 & 0.000 \\
\hline
\end{tabular}

Berdasarkan tabel diatas, variabel X1 memiliki nilai T-Statistics sebesar 10,154> THitung $(2,001)$ dan nilai $P$-Values sebesar $0,00<0,05$. Artinya hipotesis pertama (H1) diterima, dan $\mathrm{H} 0$ ditolak. Variabel X2 memliki nilai T-Statisticssebesar 30,872> THitung $(2,001)$ dan nilai $P$-Valuessebesar $0,00<0,05$. Artinya hipotesis kedua $(\mathrm{H} 2)$ diterima, dan $\mathrm{H} 0$ ditolak.

\section{PEMBAHASAN}

\section{Pengaruh Pendelegasian Wewenang(X1) terhadap Kinerja Manajerial (Y)}

NilaiT-Statistics hubungan jalur antara X1 dengan Y sebesar 10,154> T-Hitung sebesar 2,001; maka hipotesis pertama (H1) diterima.Pendelegasian wewenang berpengaruh positif dan signifikan terhadap Kinerja Manajerial. Nilai korelasi X1 dengan Y sebesar 1,201; menunjukkanPendelegasian wewenang memberikan pengaruh lemah terhadap Kinerja Manajerial. Pendelegasian wewenang mempengaruhi Y Kinerja Manajerial sebesar 12,01\%; berarti Pendelegasian wewenang berkontribusi positif hanya sebesar 12,01\% terhadap Kinerja Manajerial.

\section{Komitmen Organisasi(X2) berpengaruh terhadap Kinerja Manajerial (Y)}

Nilai T-Statistics hubungan jalur antara X2 dengan Y sebesar 30,872 >2,001; maka hipotesis $2(\mathrm{H} 2)$ diterima, Komitmen Organisasi berpengaruh positif dan signifikan terhadap Kinerja Manajerial.Nilai korelasi X2 dengan Y sebesar 1,288; berarti Komitmen Organisasi memberikan pengaruh positif yang moderat terhadap Kinerja Manajerial. Komitmen Organisasi mempengaruhi Kinerja Manajerial sebesar 12,88\%; berarti Komitmen Organisasi berkontribusi positif sebesar 12,88\% terhadap Kinerja Manajerial.Arah hubungan positif X2 terhadap Y menunjukkan bahwa semakin tinggi Komitmen Organisasi, maka semakin tinggi tingkat Kinerja Manajerial.Penelitian Dunk (1995) menyatakan bahwa Komitmen Organisasi memiliki peran positif dalam mempengaruhi hubungan kesulitan tugas dan kinerja sama halnya dengan Davila dan Wouters (2004) menyatakan bahwa adanya 
PRIMANOMICS : JURNAL EKONOMI DAN BISNIS - VOL. 17. NO. 3 (2019)

Versi Online Tersedia di : https://jurnal.ubd.ac.id/index.php/ds

| 1412-632X (Cetak) | 2614-6789 (Online) |

Komitmen Organisasi dapat mengurangi tekanan anggaran dan ketidakpastian pencapaian target anggaran yang mempengaruhi kinerja manajerial.

\section{KESIMPULAN}

Berdasar hasil penelitian dan pembahasan, maka dapat diambil kesimpulan sebagai berikut:

1. Pendelegasian wewenang berpengaruh positif signfikan terhadap Kinerja Manajerial.

2. Komitmen Organisasi berpengaruh positif signifikan terhadap Kinerja Manajerial.

\section{REFERENSI}

Abdillah, W. dan Jogiyanto, H. M., 2009. Konsep Dan Aplikasi PLS (Partial Least Square) Untuk Penelitian Empiris. Yogyakarta: Badan Penerbit Fakultas Ekonomi Dan Bisnis UGM.

Bangun, Edwin. 2015. "Pengaruh Partisipasi Anggaran, Kejelasan sasaran Anggaran dan Keadilan Distributif terhadap Kinerja Manajerial Kantor Kementrian Agama di Provinsi Lampung. Skripsi Universitas Lampung (dipublikasikan).

Bastian, Indra. 2006. Akuntansi Sektor Publik: Suatu Pengantar. Penerbit Erlangga. Jakarta. Birnberg, J.G., Shields, M.D. and Young, S.M. 1990. "The case for multiple methods in empirical management accounting research (with an illustration from budget setting)", Journal of Management Accounting Research, Fall, pp. 33-66.

Blanchette, Daniele; Claude Piote dan Jean Cadieux, 2002, Manager's moral evaluation of Budgetary slackcreation. http:// www accounting, rutgers, edu / raw.

Brownell, P. and M. Mclnes. 1986. Budgetary Participation. Motivation, and Managerial Performance. The Accounting Review.Vol.LXI Oktober.

Chin, W. W. 1998. The partial least squares approach for structural equation modeling. in G. A. Marcoulides (Ed.), Modern methods for business research (pp. 295-236). London: Lawrence Erlbaum Associates

Davila, Antonio (Tony), Wouters, Marc, 2004. Designing Cost - Competitive Technology Products Through Cost Management. Accounting Horizons. Mar, 18, 1, ABI/INFORM Research: 13,

Ferdinand, Augusty. 2006. Metode Penelitian Manajemen: Pedoman Penelitian untuk Skripsi, Tesis dan Disertasi Ilmu Manajemen. Semarang: Universitas Diponegoro.

Fernando, Richo, 2013. Pengaruh Partisipasi Penyusunan Anggaran, Motivasi, Pendelegasian wewenang, dan Komitmen Organisasi terhadap Kinerja Manajerial OPD (Studi Empris di Provinsi Lampung).

Fibrianti, Diana. 2013. Pengaruh Partisipasi Anggaran, Desentralisasi, Komitmen Organisasi, Dan Ketidakpastian Lingkungan Terhadap Kinerja Manajerial Pada Pemerintahan Kota Surabaya. Jurnal Akuntansi. Surabaya: STIESIA Surabaya.

Ghozali, Imam. 2009. Aplikasi Analisis Multivariate dengan Program SPSS. Edisi Keempat. Semarang: Badan Penerbit Universitas Diponegoro.

Greenberg \& Baron. 1993. Behavior in Organization. Prentice-Hall International Inc. London. 
Hansen dan Mowen. 2007. Akuntansi Manajemen, Edisi 7 Buku 2. Jakarta: Salemba Empat.

Hapsari, Nanda. 2010. Pengaruh Partisipasi Penyusunan Anggaran terhadap Kinerja Manajerial dengan Komitmen Organisasi dan Locus of Control sebagai Variabel Moderating. Skripsi. Fakultas Ekonomi, Universitas Diponegoro. Semarang.

Hasibuan, Malayu S. P. 2007. Manajemen Sumber Daya Manusia. Jakarta: PT Bumi Aksara

Irwan, Muhamad. 2013. Pengaruh Motivasi Kerja dan Pendelegasian Wewenang terhadap Kinerja Pegawai Kantor Dinas Pendidikan Kabupaten Indragiri Hilir. Tugas Akhir Program Magister (TAPM). Universitas Terbuka.

Kesumanjaya, Rifly, 2010. Pengaruh Pendelegasian Wewenang dan Komitmen terhadap Prestasi Kerja Karyawan pada bagian Sumber Daya Manusia (SDM) PT. Perkebunan Nusantara IV (Persero) Medan. Skripsi, Universitas Sumatera Utara, Medan.

Leslie, Kren. 1992. Budgetary Participation and Managerial Performance: The Impact of Information and Environmental Volatility. The Accounting Review Vol. 67, No. 3 July 1992. Pp 511.

Locke, E.A.,and J.F. Bryan. 1967. "Performance Goals as Determinats of Level of Performance and Boredom". Journal of Applied Psychology 51.

Lukka K. 1988. "Budgetary Biasing in Organization". Theoretical Framework and Empirical Evidence, Accounting Organization and Society 13. pp. 281-301

Mahoney, T.A., T.H. Jerdee and S.J. Caroll, (1963), Development of managerial Performance: A Research Approach, Cincinnati: South Western Publ.Co.

Marani dan Supomo. 2003. Motivasi dan Pendelegasian wewenang Sebagai Variabel Moderating Dalam Hubungan Antara Partisipasi Penyusunan Anggaran Dengan Kinerja Manajerial. Journal Riset Akuntasi Indonesia. Vol 2, Januari 2003.

Mardiasmo, 2005, Akuntansi Sektor Publik. Andi Yogyakarta.

Mediaty dan Syarifuddin. 2010. Pengaruh Partisipasi Penyusunan Anggaran Terhadap Kinerja Aparatur Pemerintah Daerah Dengan Budaya Organisasi Dan Komitmen Organisasi Sebagai Moderator (Studi Kasus Pada Pemerintah Kabupaten Barru Sul-Sel). Jurnal Ekonomi. Sulawesi Selatan.

Merchant, K.A \& Manzoni, J.F. 1989. The Achivability of Budget Targets in Profit Centers: $a$ field study. The Accounting Review, 64, 539-558.

Milani, K. 1975. "The Relationship of Participation in Budget-Setting on Industrial Supervisor Performance and Attitudes: A Field Study". The Accounting Review. April.

Milani, K.W. 1975. The Relationship of Participation in Budget-Setting to Industrial Supervisor Performance and Attitudes: a Field Study. The Accounting Review, 50(2), pp. 274-284..

Mowday, R. T., Steers, R. M.,\&Porter, L.W. 1979,. The measurement of organizational commitment. Journal of Vocational Behavior, 14, 224-247.

Mowen / Hansen. 2013. Akuntansi Manajerial. Jakarta: Salemba Empat.

Mulyadi, 2001. Sistem Akuntansi, Edisi Ketiga. Jakarta: Salemba Empat. 
PRIMANOMICS : JURNAL EKONOMI DAN BISNIS - VOL. 17. NO. 3 (2019)

Versi Online Tersedia di : https://jurnal.ubd.ac.id/index.php/ds

| 1412-632X (Cetak) | 2614-6789 (Online) |

Nanda, Irfan dkk, 2013. Pengaruh Komitmen Organisasional terhadap Prestasi Kerja (Studi Pada Karyawan AJB Bumiputera Kantor Cabang Batu). Universitas Brawijaya, Vol.6 No.2.

Nouri, H. dan R. J. Parker. 1998. The Relationship Between Budget Participation And Job Performance: The Roles Of Budget Adequacy And Organizational Commitment. Accounting, Organization and Society. Vol 23. No5/6 pp.467-483.

Onsi, M. 1973. Factor Analysis of Behavioral Variables Affecting Budgetary Slack. The Accounting Review. July. Pp. 535-548

Putri, Yolanda, G. 2013. Pengaruh Komitmen Organisasi dan Sistem Pengendalian Intern Pemerintah (SPIP) terhadap Kinerja Manajerial SKPD (Studi Empiris pada Satuan Kerja Perangkat Daerah Kota Padang) Ramandei, Pilipus. 2009. Pengaruh Karakteristik Sasaran Anggaran dan Sistem Pengendalian Intern terhadap Kinerja Manajerial Aparat Pemerintah Daerah Kota Jayapura. (Thesis)

Riyadi, Slamet. 2000. "Motivasi Dan Pendelegasian wewenang sebagai Moderating dalam Hubungan antara Partisipasi Penyusunan Anggaran dan Kinerja Manajerial. Jurnal Riset Akuntansi Indonesia, Vol. 3, No. 2, Hal.134-150.

Robbins, Stephen R, Timothy A. Judge. 2009. Perilaku Organisasi. Jakarta: Salemba Empat.

Ryninta, M.G dan Zulfikar. 2005. Pengaruh Pendelegasian wewenang terhadap Hubungan antara Kinerja Manajerial dan Partisipasi Penyusunan Anggaran (Studi Empiris pada Rumah Sakit di Kotamadya Surakarta). Jurnal Akuntansi dan Keuangan. Vol. 4. No. 2. Hal. 156-174.

Sardjito, Bambang dan Muthaher Osmad. 2007. "Pengaruh Partisipasi Penyusunan Anggaran terhadap Kinerja Aparat Pemerintah Daerah: Budaya Organisasi dan Komitmen Organisasi Sebagai Variabel Moderating", Jurnal Ekonomi dan Bisnis, olume 2 Nomor 1, Halaman 37-49.

Schiff, M. and A.W. Lewin. 1970. The Impact of People on Budgets. The Accounting Review. Vol. 45, pp. 259-268.

Sedarmayanti. 2004. Good Governance (Kepemerintahan yang baik). Bandung: Munandar Maju.

Sekaran, Uma. 2014. Metodologi Penelitian untuk Bisnis (Research Methods for Business). Buku 1 Edisi 4. Jakarta: Salemba Empat.

Suartana, I Wayan, 2010. Akuntansi Keprilakuan Teori dan Implementasi, Cetakan Pertama, Andi Offset, Denpasar.

Sugiyono. 2013. Metode Penelitian Kuantitatif, Kualitatif dan RED. Bandung : Alfabeta.

Sumarno, J. 2005. Pengaruh Komitmen Organisasi dan Gaya Kepemimpinan terhadap Hubungan antara Partisipasi Anggaran dan Kinerja Manajerial. Jurnal Bisnis Strategi, Vol. 14, no. 2, Desember 2005

Syafrial. 2009. Pengaruh Ketepatan Skedul Penyusunan Anggaran, Kejelasan Sasaran Anggaran, dan Partisipasi Penyusunan Anggaran terhadap Kinerja Manajerial OPD pada Pemerintah Kabupaten Sarolangun. Tesis. Sekolah Pascasarjana Universitas umatera Utara. 
Wulandari, Nur Endah. 2011. "Pengaruh Partisipasi Penyusunan Anggaran Terhadap Kinerja Aparat Pemerintah Daerah: Kepuasan Kerja Dan Komitmen Organisasi Sebagai Variabel Moderating (Studi Empiris Pada Pemerintah Daerah Kabupaten Demak)". Skripsi Universitas Diponegoro (dipublikasikan)

Young, S.M. 1985. Participative Budgeting: The Effect of Risk Aversion and Assymetric Information on Budgetary Slack. Journal of Accounting Research, Vol. 23: 829-842. 